\title{
Managing fatigue in patients with Parkinson's disease: a patient-focused perspective
}

This article was published in the following Dove Press journal: Journal of Parkinsonism and Restless Legs Syndrome 6 July 2016

Number of times this article has been viewed

\author{
Andrew Ridder ${ }^{\prime}$ \\ Kelvin L Chou ${ }^{1,2}$ \\ 'Department of Neurology, \\ ${ }^{2}$ Department of Neurosurgery, \\ University of Michigan, Ann Arbor, MI, \\ USA
}

\begin{abstract}
Fatigue, experienced as a significantly diminished energy level or an increased perception of effort disproportionate to attempted activities or general activity level, is being increasingly recognized as a common and disabling problem in patients with Parkinson's disease. There are no commonly accepted criteria to diagnose fatigue in Parkinson's disease and there is limited evidence regarding treatment of this symptom. This article reviews the current knowledge surrounding fatigue in Parkinson's disease, including symptoms, epidemiology, diagnosis, and treatment, with a focus on the patient's perspective.
\end{abstract}

Keywords: Parkinson's disease, fatigue, diagnosis, treatment

\section{Introduction}

The term "fatigue" can be interpreted differently between different patients. It has been used throughout the medical literature to refer to many disparate symptoms. In common usage, fatigue generally refers to difficulty initiating or maintaining focus on an activity or to a feeling of disconnection between what a person perceives they should be able to do and with what they can do. ${ }^{1}$ Most people experience this feeling at some point, and it represents a physiologic reaction to physical or emotional stress. This feeling improves with rest and does not interfere with daily life. As a medical complaint, however, fatigue is more complex. It may refer to a sense of inability to start or maintain normal activities in the absence of significant activity or it is described as a "lack of energy" or exhaustion in the face of activity. Improvement with rest is much less robust. ${ }^{2}$ Fatigue in this sense can significantly interfere with activities of daily life. Many patients with fatigue do not endorse apathy or a lack of motivation to perform activities, just the lack of energy. ${ }^{3}$ It is this type of fatigue that is a frequent non-motor symptom of Parkinson's disease (PD) and other chronic illnesses. ${ }^{1,4-6}$

Fatigue has only been recently recognized as a common problem in PD. ${ }^{7,8}$ Over half of PD patients consider fatigue among their most disabling symptoms, ${ }^{8-10}$ and yet fatigue often goes unrecognized and is not addressed by neurologists. ${ }^{11}$ In this paper, we will review the current knowledge surrounding fatigue in PD, including symptoms, epidemiology, diagnosis, and treatment, with a focus on the patient's perspective.

\section{What is fatigue from a PD patient's perspective?}

Throughout the approximately 10-year course of my illness, I have experienced symptoms of worsening fatigue and exhaustion. The amount of fatigue I experience is generally correlated with my level of physical and mental activity, as well as stress, but is not
Correspondence: Kelvin L Chou of Michigan Medical School, 2301

Commonwealth Blvd, Ann Arbor, MI 481052945 , USA

Tel +l 7349363087

Fax+I 734232 II 70

Email klchou@med.umich.edu 
entirely predictable. One thing I can count on is that fatigue occurs daily and worsens as the day goes on. My stamina and clarity are significantly impaired during the bouts of fatigue and at those times I try to avoid interactions professionally and with family and friends. The result is a significantly decreased quality of life. [Personal communication from patient with PD on living with fatigue]

There are multiple terms used throughout the medical literature in attempts to better quantify fatigue and study possible interventions. ${ }^{1,12}$ As an example, mental fatigue refers to the perception of cognitive slowing or difficulty with concentration, while physical fatigue is a difficulty initiating or sustaining voluntary actions. ${ }^{6}$ Fatigue may also be split into central and peripheral subtypes. Central fatigue may refer to decreased recruitment of muscles secondary to motor cortex failure, central conduction block from demyelination, reduced central drive, reduced coordination of motor unit firing, or decreases in joint flexibility from spasticity, and includes mental fatigue. It has also been described as a "failure of physical and mental tasks that require self-motivation and internal cues in the absence of demonstrable cognitive failure or motor weakness". ${ }^{13}$ Peripheral fatigue refers to a loss of muscle contraction force or atrophy. ${ }^{1}$ There is also the term "fatigability", which is defined as a decrease in performance of an activity over time usually in terms of strength, accuracy, or speed. ${ }^{14,15}$

These terms illustrate the difficulty that medical professionals have in defining fatigue. Patients have an even harder time describing this phenomenon. ${ }^{9}$ When developing the Parkinson Fatigue Scale, Brown et $\mathrm{al}^{9}$ conducted a series of focus groups with patients in order to elicit comments on their perception of fatigue. The adjectives used to describe the fatigue included "tiredness", "lack of energy", "exhaustion", "heavy", and "drained". These feelings could be separated from normal states of tiredness as well as from sleepiness. For fatigue severity, terms such as "extreme" or "total" were used, suggesting that the intensity of fatigue may be a prominent part of their experience. ${ }^{6}$ Because of the difficulty in defining fatigue, many scales that assess fatigue do not define it explicitly but ask about how fatigue affects a patient's life, utilizing the patient's own definition. ${ }^{16}$ This lack of a standard definition has certainly made research on PD fatigue more difficult. However, the fact remains that the subjective experience of fatigue substantially affects the lives of many patients with PD.

\section{Who gets fatigue in PD and what is its impact?}

The prevalence of fatigue is difficult to estimate, as the symptoms occur on a continuum from an expected and transient result of strenuous activity to a debilitating, life-altering symptom. We report the prevalence of the subjective experience of global fatigue that can impact daily life, since that is most relevant to the patient. The prevalence of fatigue in the general population is between $5 \%$ and $56 \%,{ }^{1}$ and the prevalence of chronic fatigue is between $2 \%$ and $11 \%$, depending on the study. ${ }^{17}$ In $\sim 10 \%$ of primary care office visits, fatigue is the presenting complaint. ${ }^{6}$ Prevalence of fatigue increases with medical comorbidities and age. ${ }^{17}$ It is more common in neurologic disease, occurring with a frequency between $75 \%$ and $89 \%$ in myasthenia gravis and between $38 \%$ and $83 \%$ in multiple sclerosis. It has the highest prevalence in cancer patients, up to $90 \%-100 \%$, especially in those undergoing chemotherapy or radiation treatments. ${ }^{1}$

While fatigue was recognized as a part of PD by some of the major clinical neurologists of the 19 th century, ${ }^{18}$ recent reports demonstrate that patients consider fatigue to be one of the most frequent and debilitating non-motor symptoms of PD. It may predate and be more bothersome than the motor symptoms in some patients. ${ }^{19-21}$ Between $35 \%$ and $75 \%$ of PD patients experience fatigue. ${ }^{1,22}$ In PD patients who experience it early in their disease course, fatigue worsens with disease duration, but patients without early fatigue tend not to develop it later. ${ }^{6,22-25}$ The severity of fatigue does not correlate with motor symptoms, and improving motor symptoms does not always reduce fatigue. ${ }^{3,26,27} \mathrm{PD}$ patients with fatigue have a significantly poorer health-related quality of life, although controlling for depression and anxiety reduces the effect. ${ }^{10,13,20}$

Fatigue is part of the diagnostic criteria for depression and generalized anxiety disorder and separating these symptoms can be difficult. ${ }^{8,28,29}$ Mood disorders are also among the most common non-motor symptoms in PD, which are reported in up to $65 \%-70 \%$ of patients. ${ }^{22}$ Fatigue, anxiety, and depression in PD have significant clinical overlap and all independently have a negative impact on quality of life. ${ }^{10,30,31}$ This suggests that treating anxiety and depression may improve fatigue. However, PD-related fatigue does not always respond to the treatments of anxiety and depression and can be separated from mood as an independent symptom. ${ }^{32}$

The interdependence of sleep and fatigue is another important and sometimes confounding factor. Sleep disorders are very common in PD. These include rapid eye movement (REM) sleep behavior disorder $(15 \%-59 \%),{ }^{33}$ sleep fragmentation, insomnia (up to $80 \%$ ), ${ }^{34}$ restless legs syndrome, periodic limb movements of sleep, obstructive sleep apnea, and excessive daytime sleepiness. ${ }^{22,26,33,35}$ Excessive daytime sleepiness is often confused with fatigue in the medical 
literature, ${ }^{36-38}$ but as mentioned earlier, PD patients with fatigue can separate this feeling from sleepiness. Furthermore, rating scales for excessive daytime sleepiness and fatigue differ and patients with these symptoms show differing responses to treatments. ${ }^{33}$ The symptoms of excessive daytime sleepiness in PD are more diurnal compared to that of fatigue. ${ }^{22,34}$ In fact, increased sleep in PD patients correlates with worsened fatigue and daytime sleepiness in some studies. ${ }^{33}$

\section{How is fatigue diagnosed in PD?}

Because the pathophysiology of fatigue in PD is unknown, there are no tests that allow for a diagnosis of fatigue. There are also no commonly accepted criteria on how to define clinically significant fatigue in PD. A Parkinson Disease Foundation working group recently developed a case definition of PD-related fatigue based on expert opinion (Table 1), ${ }^{39}$ in accordance with the Diagnostic and Statistical Manual IV style used for defining cancer-related fatigue and chronic fatigue syndrome. ${ }^{40,41}$ At the core of this definition is a daily or nearly daily feeling of significantly diminished energy or an increased perception of effort disproportionate to attempted activities or general activity level. Additionally, patients must experience at least four of the nine symptoms in Section A, as well as meet criteria in Sections B, C, and $\mathrm{D}$. These criteria have not yet been validated, but they provide a foundation for diagnosing PD-related fatigue in a consistent fashion.

Validated scales may help with the recognition of PD fatigue by screening for symptoms. Validated fatigue measures are also needed in order to track fatigue intensity on a consistent basis, as well as to track the response to therapeutic interventions. The Movement Disorders Society Task
Force on Rating Scales for Parkinson's Disease conducted a critical review of existing scales for fatigue in $2010 .{ }^{42}$ A total of nine scales that had been applied to PD fatigue research were critiqued: the Fatigue Severity Scale (FSS), ${ }^{16}$ the Fatigue Assessment Inventory (FAI), ${ }^{43}$ the Functional Assessment of Chronic Illness Therapy - Fatigue Scale (FACIT-F), ${ }^{44}$ the Multidimensional Fatigue Inventory (MFI), ${ }^{45}$ the Parkinson's Fatigue Scale (PFS), ${ }^{9}$ the Fatigue Severity Inventory (FSI), ${ }^{46}$ the Fatigue Impact Scale for Daily Use (D-FIS), ${ }^{47}$ Visual Analogue Scale (VAS), ${ }^{8}$ and the Clinical Global Impression Scale (CGIS). ${ }^{48}$ The Task Force rated the scale as "recommended", "suggested", or "listed" based on three criteria: 1) whether the scale had been applied to PD populations, 2) whether there were data in clinical studies beyond the group that developed the scale, and 3) whether it had been studied psychometrically in PD. "Recommended" scales met all three criteria. "Suggested" scales met the first criterion and one of the other two criteria. "Listed" scales met only the first criterion. The scales were evaluated relative to their ability to screen for fatigue in PD and measure severity of fatigue. The FAI, D-FIS, FSI, VAS, and CGIS all failed to receive a designation of "recommended" in either category.

The FSS was the only scale to be "recommended" for both diagnostic screening and severity measurement of fatigue. The FSS is a generic, self-administered, nine-item rating scale, with each item rated on a seven-point Likert scale. The total FSS score is the mean of each of the nine items and is the most frequently used fatigue-specific scale in chronic disease, including PD. ${ }^{15}$

The MFI was "recommended" for rating fatigue severity in PD, but not for diagnostic screening. It is a 20 -item self-administered rating scale with five dimensions and has

Table I Criteria for diagnosis of Parkinson's disease-related fatigue

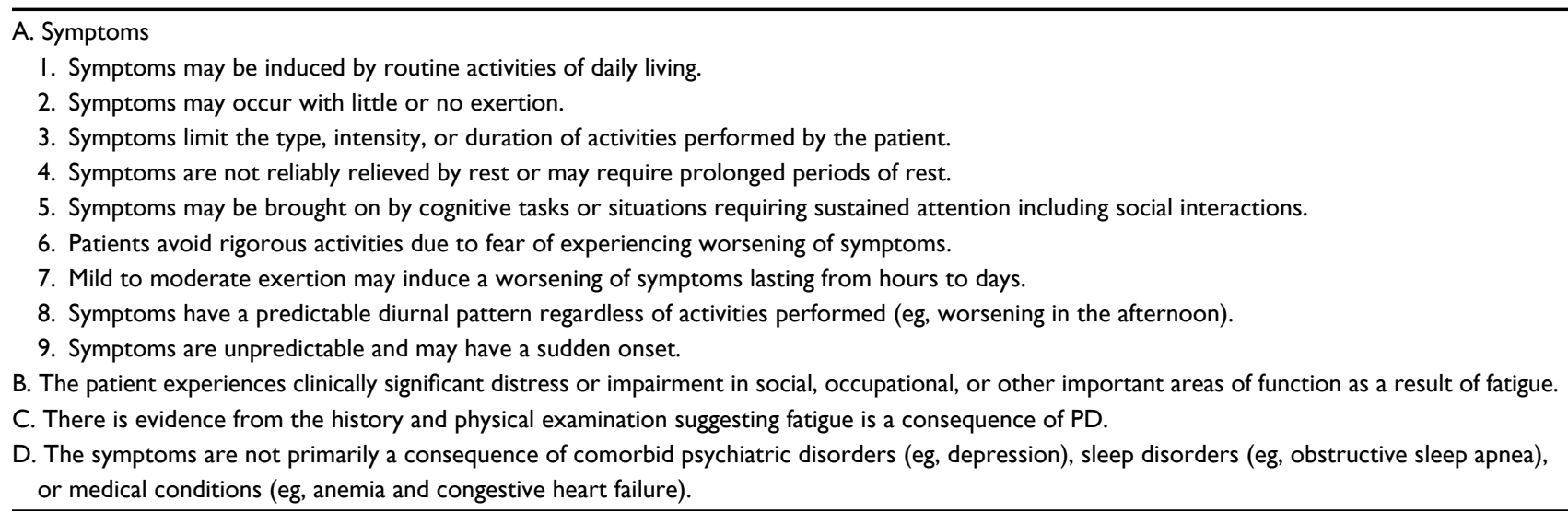

Notes: Patients must report significantly diminished energy levels or increased perceptions of effort which are disproportionate to attempted activities or general activity level. Symptoms must be present for most of the day, every day, or nearly every day during the previous month. In addition, patients must have four or more of the symptoms from Section A as well as meet criteria in Sections B, C, and D. Reproduced from Kluger BM, Herlofson K, Chou KL, et al. Parkinson's disease-related fatigue: a case definition and recommendations for clinical research. Mov Disord. 2016;31(5):625-631. ${ }^{39}$ With permission from John Wiley and Sons, (C) 2016.

Abbreviation: PD, Parkinson's disease. 
Table 2 Randomized controlled trials investigating treatments for fatigue in PD

\begin{tabular}{|c|c|c|c|c|c|c|c|c|c|}
\hline Study & Intervention & $\mathbf{n}$ & $\begin{array}{l}\text { Mean } \\
\text { age (SD) }\end{array}$ & Male (\%) & $\begin{array}{l}\text { Years since } \\
\text { diagnosis (SD) }\end{array}$ & $\begin{array}{l}\text { Hoehn \& } \\
\text { Yahr (SD) }\end{array}$ & $\begin{array}{l}\text { Fatigue is } \\
\text { primary } \\
\text { outcome }\end{array}$ & $\begin{array}{l}\text { Fatigue } \\
\text { scale }\end{array}$ & $\begin{array}{l}\text { Effect on } \\
\text { fatigue }\end{array}$ \\
\hline Lou et $\mathrm{al}^{74}$ & Modafinil & 19 & $66.8(8.5)$ & 76 & $6.1(5.1)$ & $2.0(0.6)$ & $Y$ & MFI, FSS & None \\
\hline Ondo et $\mathrm{al}^{75}$ & Modafinil & 37 & $64.8(11.3)$ & 72 & $6.8(5.0)$ & NR & $Y$ & FSS & None \\
\hline Tyne et $\mathrm{a}^{76}$ & Modafinil & 13 & 59.1 (NR) & 69 & $7(5)$ & $2.2(\mathrm{NR})$ & $\mathrm{Y}$ & FSS & None \\
\hline Mendonca et $\mathrm{a}^{55}$ & Methylphenidate & 36 & 64.1 & 67 & $N R$ & $2.49(0.42)$ & $\mathrm{Y}$ & FSS, MFI & Small positive \\
\hline Rios Romenets et $\mathrm{a}^{32}$ & Doxepin & 18 & $64.4(12.4)$ & 78 & $5(3.3)$ & $N R$ & $\mathrm{~N}$ & FSS & Moderate positive \\
\hline $\begin{array}{l}\text { Rascol et a }\left.\right|^{58} \text { and } \\
\text { Olanow et al }\left.\right|^{77, a}\end{array}$ & Rasagiline & 1176 & $62.2(9.7)$ & 61 & $0.375(0.38)$ & I.5। (0.5) & $N$ & PFS & Positive \\
\hline Schifitto et $\mathrm{al}^{59}$ & Levodopa & 349 & $64.5(10.92)$ & 68 & $0.52(0.54)$ & I.8 (0.55) & $\mathrm{N}$ & FSS & None \\
\hline Ray Chaudhuri et al ${ }^{60}$ & Rotigotine & 267 & $64.6(9.72)$ & 66 & $4.8(4.43)$ & NR & $N$ & NMSS & Small positive \\
\hline Ondo et $\mathrm{a}^{62}$ & Memantine & 40 & $69.1(7.8)$ & 60 & $N R$ & $2.4(0.48)$ & $Y$ & FSS & None \\
\hline Postuma et al ${ }^{54}$ & Caffeine & 61 & $66.5(9.88)$ & 72 & $7.9(4.18)$ & NR & $\mathrm{N}$ & FSS & None \\
\hline Ondo et $\mathrm{a}^{64}$ & Sodium oxybate & 30 & $61.5(8.7)$ & 80 & $8.6(5.5)$ & $2.35(0.37)$ & $\mathrm{N}$ & ESS, FSS & Positive \\
\hline Ghahari et al ${ }^{72, b}$ & $\begin{array}{l}\text { Behavioral } \\
\text { program }\end{array}$ & 95 & $50.25(12.3)$ & & II.44 (13.4) & NR & $Y$ & FSS & None \\
\hline Rios Romenets et $\mathrm{a}^{32}$ & CBT & 18 & $66.4(12.4)$ & 78 & $5.0(3.3)$ & NR & $N$ & FSS & None \\
\hline Winward et al ${ }^{69}$ & Exercise & 39 & $64.1(8.17)$ & 79 & $5.79(4.27)$ & NR & $Y$ & FSS & None \\
\hline Canning et $\mathrm{a}^{68}$ & Exercise & 22 & $61.8(8.0)$ & 55 & $5.65(3.97)$ & NR & $N$ & VAS & None \\
\hline Cugusi et $\mathrm{al}^{70}$ & $\begin{array}{l}\text { Exercise (Nordic } \\
\text { walking) }\end{array}$ & 20 & $67.3(7.8)$ & 80 & $7(3)$ & $2.35(0.65)$ & $Y$ & PFS & Positive \\
\hline Kluger et $\mathrm{al}^{71}$ & Acupuncture & 94 & $63.7(11.7)$ & 59 & NR & $2.30(0.65)$ & $Y$ & MFIS, ESS & $\begin{array}{l}\text { Positive in both } \\
\text { groups, but } \\
\text { no difference } \\
\text { between groups }\end{array}$ \\
\hline
\end{tabular}

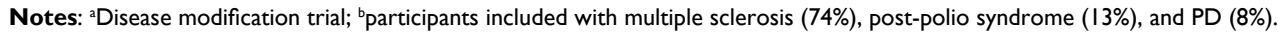

Abbreviations: PD, Parkinson's disease; ESS, Epworth Sleepiness Scale; FSS, Fatigue Severity Scale; MFI, Multidimensional Fatigue Inventory; NMSS, Non-Motor Symptom Scale; PFS, Parkinson's Fatigue Scale; VAS, Visual Analog Scale; MFIS, Modified Fatigue Impact Scale; NR, not reported; Y, yes; N, no; CBT, cognitive behavioral therapy.

been used in 14 studies of patients with PD. In contrast, the FACIT-F and PFS were both "recommended" for diagnostic screening but not for evaluation of fatigue severity. The FACIT-F was originally developed in a cancer population. It consists of 13 items with five ordered responses for each item. Total scores for the FACIT-F range from 0 to 52, with higher scores representing less fatigue. The PFS was developed to evaluate the physical aspects of fatigue in PD and is a 16-item self-administered scale. The items are rated on a 1-5 scale. The total PFS score is the average score across all 16 items, though an alternative binary scoring method can also be used.

In addition, the developers of the Movement Disorder Society-sponsored Unified PD Rating Scale included an item on fatigue in the scale. ${ }^{49}$ It asks whether subjects have usually felt fatigued over the past week and whether they were able to differentiate it from being sleepy or sad. The fatigue is rated on a $0-4$ scale, with anchors describing the severity of the fatigue.

All of the above scales are attempts to objectify the subjective experience of fatigue. While objective measures of motor fatigability exist, such as sustained muscle contractions or repetitive movements, motor fatigability typically does not correlate with subjective fatigue, ${ }^{50,51}$ so motor fatigability measures are unlikely to be used clinically to help diagnose or document the severity of PD-related fatigue.

\section{How is fatigue managed in PD?}

A recent Cochrane review evaluated clinical trials of both pharmacologic and non-pharmacologic interventions on fatigue in PD. ${ }^{52}$ Unfortunately, the number of randomized, controlled, clinical trials on PD-related fatigue reported in the literature is limited, especially those with fatigue as a primary outcome measure. Typically, fatigue is reported as a secondary outcome. Other limitations of these studies include small sample sizes, different definitions of fatigue, and inconsistent accounting for confounding variables, such as depression and sleep. Pharmacologic therapies for PD-related fatigue that have been studied in a randomized, controlled fashion include stimulants/wake-promoting agents, dopaminergic agents, antidepressants, and others (eg, memantine and sodium oxybate). Randomized, controlled trials of non-pharmacologic therapies include exercise, acupuncture, and cognitive behavioral therapy. These clinical trials are summarized in Table 2. There has been no randomized, controlled clinical trial of deep brain stimulation on PD-related fatigue, but one study showed no 
change in PFS scores 6 months after bilateral subthalamic nucleus deep brain stimulation. ${ }^{53}$

\section{Stimulants/wake-promoting agents}

Stimulants and wake-promoting agents, including caffeine, methylphenidate, and modafinil, are the most studied pharmacologic intervention for fatigue in PD. Postuma et al studied the effect of caffeine at $100 \mathrm{mg}$ twice a day for 3 weeks and then at $200 \mathrm{mg}$ twice a day for 3 weeks. ${ }^{52,54}$ At the end of the study, there was no difference between caffeine and placebo groups in terms of fatigue, sleepiness, or depression. Caffeine did not cause increased side effects compared to placebo, but it resulted in a clinically significant improvement in Unified PD Rating Scale scores. ${ }^{54}$ Mendonca et al investigated the effect of methylphenidate on fatigue scores in 34 patients with PD. ${ }^{52,55}$ While methylphenidate significantly lowered both FSS and MFI scores after 6 weeks of treatment, ${ }^{55}$ there were no statistically significant differences between the methylphenidate and placebo groups after 6 weeks of treatment. ${ }^{52}$ There is also concern for abuse in PD patients with methylphenidate, especially those with impulse control problems and those on dopamine agonists already. ${ }^{55}$

Three studies included in the Cochrane review looked at modafinil, a wake-promoting agent thought to act through the dopamine and noradrenergic systems, possibly through orexin/ hypocretin pathways. ${ }^{33,56}$ When pooled together, there was no statistically significant difference found between modafinil and placebo on fatigue impact, ${ }^{52}$ though there was more of an effect in depressed patients (and it slightly improved their depression). Pooled data did show a clinically significant decrease in Epworth Sleepiness Scale (ESS) scores, although objective sleepiness measures (sleep latency and maintenance of wakefulness) were unchanged. ${ }^{33,52} \mathrm{~A}$ review of modafinil for fatigue in neurologic disorders including multiple sclerosis, PD, post-polio syndrome, and traumatic brain injury (TBI) found a slight improvement in fatigue only in the TBI population. ${ }^{56}$

\section{Dopaminergic agents}

Rasagiline is a monoamine oxidase inhibitor that has been used in the treatment of motor fluctuations and some nonmotor symptoms ${ }^{57}$ and has been looked at for fatigue. In the ADAGIO study, a large $(n=1,176)$ randomized controlled trial investigating rasagiline at doses of $1-2 \mathrm{mg}$ /day over 36 weeks of treatment, there was an improvement in physical fatigue in the rasagiline group compared to placebo, without an increase in side effects. ${ }^{52,58}$ However, this study was designed to look for disease-modifying effects; fatigue was not the primary outcome. Also, the fatigue severity in the rasagiline group did not improve per se; the placebo group became significantly more fatigued. ${ }^{58}$
As part of the ELLDOPA study, Schifitto et al examined fatigue in the 349 subjects who completed fatigue measures. ${ }^{59}$ These subjects were randomized to placebo or three different doses of carbidopa-levodopa. While FSS scores increased more in the placebo group than in the levodopa groups, this did not meet statistical significance. ${ }^{52}$ The results were limited by inclusion of many non-fatigued patients in all arms of the trial, which could blunt the effects compared to looking at only patients with fatigue.

The RECOVER study was a randomized controlled trial of 287 PD patients randomized to rotigotine - a non-ergot dopamine agonist transdermal patch - vs placebo.$^{60}$ In a post hoc analysis, a significant improvement in the sleep/fatigue domain of the Non-Motor Symptom Scale was found in the rotigotine group compared to the placebo group. However, it is unclear if dopamine agonists can be used successfully for PD fatigue, since fatigue is a common side effect of other agonists, including ropinirole and pramipexole. ${ }^{61}$

\section{Antidepressants}

Many studies have looked at antidepressants in PD, but very few have fatigue as an outcome measure. ${ }^{52}$ One study investigating doxepin, a tricyclic antidepressant, was included in the Cochrane review. In this study, 18 patients were randomized ( six each) to placebo, doxepin, and cognitive behavioral therapy. At the end of 6 weeks, doxepin decreased the impact of fatigue on activities of daily living and fatigue severity, as measured by the FSS, without significant risk of side effects. ${ }^{32}$ Unfortunately, the study was not sufficiently blinded, introducing substantial risk of bias. ${ }^{52}$

\section{Other agents}

Ondo et al investigated the effects of memantine, an $\mathrm{N}$-methyl-d-aspartate receptor antagonist, on fatigue, but they found no effect. ${ }^{62,52}$ They also studied sodium oxybate, a metabolite of $\gamma$-aminobutyric acid with central nervous system depressant properties and a salt of $\gamma$-hydroxybuterate (the "date-rape drug"), which is approved by US Food and Drug Administration (FDA) for narcolepsy and has been evaluated for fatigue symptoms in fibromyalgia and PD. ${ }^{63}$ In this study, the sodium oxybate group showed a significant decrease in both ESS and FSS as well as increased Stage III non-REM sleep and decreased REM sleep on polysomnography. ${ }^{64}$ However, this is a highly regulated and potentially dangerous drug. In the study, there was a clinically significant increase in apnea-hypopnea index in several patients. It also has a black box warning for being both a central nervous system depressant and for significant abuse potential. ${ }^{33}$ 


\section{Non-pharmacologic therapies}

Exercise and dance have been looked at as a treatment for nonmotor symptoms in general, but there are only a few randomized, controlled trials focused on fatigue as an outcome measure. ${ }^{52}$ Some actually include fatigue as an adverse event. The many studies on dance interventions in PD patients have focused strongly on motor outcomes and none specifically on fatigue. ${ }^{65}$

Some epidemiologic and small, noncontrolled studies show an inverse correlation between exercise and fatigue scores. ${ }^{66,67}$ An open label study involving nine PD patients showed a decrease of $17.5 \%$ in the PFS (from 4.0 to 3.3 points) after participating in 60-70 minutes of exercise three mornings a week for 9 weeks. ${ }^{67}$ However, randomized, controlled trials comparing treadmill or strength exercises to normal care have generally shown no improvement on fatigue scores. ${ }^{52,68,69}$ Cugusi et al randomized 20 PD patients to a twice-a-week Nordic walking program vs conventional care and found a $17.2 \%$ improvement in PFS-16 scores (48.8-40.4 points) in the Nordic walking group compared to controls over a 12-week course. ${ }^{70}$ The authors suggested that frequent or strenuous exercise may cause increased physical fatigue (as seen in other trials) and that exercise programs should be tailored to the individual patient instead..$^{70}$

A recent randomized controlled trial of acupuncture in PD patients found significant improvement in the Modified Fatigue Impact Scale in both real and sham acupuncture groups, but no between-group differences were observed. ${ }^{71}$ The authors concluded that "acupuncture likely confers benefit through placebo or other nonspecific effects" and left the decision to the reader to consider it for fatigue treatment based on its effects. A single study on cognitive behavioral therapy and another study comparing an online fatigue management program with controls showed no improvement in fatigue scores. ${ }^{32,72}$

\section{A practical approach to managing fatigue}

Given the limited evidence detailed earlier regarding the treatment of PD fatigue, we propose the following approach. First, it is important to recognize fatigue and let patients know that many others with PD experience fatigue. Because of the overlap of fatigue with depression, anxiety, and sleep disorders, attempts should be made to treat these confounding factors, which by themselves may help fatigue. ${ }^{33}$ Despite the limited number of randomized controlled trials showing a benefit of exercise for fatigue thus far, we would still recommend exercise as part of the treatment regimen for fatigue, as it has benefits on other aspects of PD and because PD patients often feel that exercise alleviates fatigue. ${ }^{73}$

\section{Conclusion}

Fatigue is a common and debilitating problem in PD. It is experienced as a significant lack of energy and may worsen with even mild activities. While the underlying pathophysiology of fatigue in PD is not well understood, it appears to present in patients early on and worsens with time. The impact on quality of life is significant. There is a clear need for further research in both understanding the underlying mechanism and finding new treatments, and this review cannot recommend any treatments strongly. A multidimensional approach focused on treating sleep and psychiatric disorders as well as fatigue is likely to be the most effective.

\section{Disclosure}

Dr Chou receives research support from the National Institute of Health (grants NS044504-08 and NS091856-01) and the Michael J Fox Foundation, participates as a site-principal investigator in clinical trials sponsored by the Huntington Study Group (2CARE) and Parkinson Study Group (STEADY-PDIII), receives royalties from UpToDate, receives royalties from Demos Health for his book Deep Brain Stimulation; A New Life for People with Parkinson's, Dystonia, and Essential Tremor, and serves as a consultant for Accordant, Advanced Medical, and Cynapsus Therapeutics.

The authors report no other conflicts of interest in this work.

\section{References}

1. Finsterer J, Mahjoub SZ. Fatigue in healthy and diseased individuals. Am J Hosp Palliat Care. 2014;31(5):562-575.

2. Bower JE. Fatigue, brain, behavior, and immunity: summary of the 2012 Named Series on fatigue. Brain BehavI Immun. 2012;26(8):1220-1223.

3. Akbar U, Friedman JH. Recognition and treatment of neuropsychiatric disturbances in Parkinson's disease. Expert Rev Neurother. 2015;15(9):1053-1065.

4. Zingone F, Swift GL, Card TR, Sanders DS, Ludvigsson JF, Bai JC. Psychological morbidity of celiac disease: a review of the literature. United European Gastroenterol J. 2015;3(2):136-145.

5. Kwakkenbos L, Delisle VC, Fox RS, et al. Psychosocial aspects of scleroderma. Rheum Dis Clin North Am. 2015;41(3):519-528.

6. Friedman JH, Brown RG, Comella C, et al. Fatigue in Parkinson's disease: a review. Mov Disord. 2007;22(3):297-308.

7. van Hilten JJ, Hoogland G, van der Velde EA, Middelkoop HA, Kerkhof GA, Roos RA. Diurnal effects of motor activity and fatigue in Parkinson's disease. J Neurol Neurosurg Psychiatry. 1993;56(8):874-877.

8. Friedman J, Friedman H. Fatigue in Parkinson's disease. Neurology. 1993;43(10):2016-2018.

9. Brown RG, Dittner A, Findley L, Wessely SC. The Parkinson fatigue scale. Parkinsonism Relat Disord. 2005;11(1):49-55.

10. Dogan VB, Koksal A, Dirican A, Baybas S, Dirican A, Dogan GB. Independent effect of fatigue on health-related quality of life in patients with idiopathic Parkinson's disease. Neurol Sci. 2015;36(12):2221-2226.

11. Shulman LM, Taback RL, Rabinstein AA, Weiner WJ. Non-recognition of depression and other non-motor symptoms in Parkinson's disease. Parkinsonism Relat Disord. 2002;8(3):193-197.

12. Falup-Pecurariu C. Fatigue assessment of Parkinson's disease patient in clinic: specific versus holistic. J Neural Transm. 2013;120(4):577-581. 
13. Friedman JH. Fatigue in Parkinson's disease patients. Curr Treat Options Neurol. 2009;11(3):186-190.

14. Kluger BM, Parra V, Jacobson C, et al. The prevalence of fatigue following deep brain stimulation surgery in Parkinson's disease and association with quality of life. Parkinson's Dis. 2012;2012:769506.

15. Kluger BM, Krupp LB, Enoka RM. Fatigue and fatigability in neurologic illnesses: proposal for a unified taxonomy. Neurology. 2013;80(4):409-416.

16. Krupp LB, LaRocca NG, Muir-Nash J, Steinberg AD. The fatigue severity scale. Application to patients with multiple sclerosis and systemic lupus erythematosus. Arch Neurol. 1989;46(10):1121-1123.

17. Manty M, Rantanen T, Era P, Avlund K. Fatigue and depressive symptoms in older people. J Appl Gerontol. 2014;33(4):505-514.

18. Garcia-Ruiz PJ, Chaudhuri KR, Martinez-Martin P. Non-motor symptoms of Parkinson's disease A review... from the past. J Neurol Sci. 2014;338(1-2):30-33.

19. Elbers R, van Wegen EE, Rochester L, et al. Is impact of fatigue an independent factor associated with physical activity in patients with idiopathic Parkinson's disease? Mov Disord. 2009;24(10):1512-1518.

20. Elbers RG, van Wegen EE, Verhoef J, Kwakkel G. Impact of fatigue on health-related quality of life in patients with Parkinson's disease: a prospective study. Clin Rehabil. 2014;28(3):300-311.

21. Miwa H, Miwa T. Fatigue in patients with Parkinson's disease: impact on quality of life. Int Med. 2011;50(15):1553-1558.

22. Ou R, Yang J, Cao B, et al. Progression of non-motor symptoms in Parkinson's disease among different age populations: a two-year follow-up study. J Neurol Sci. 2016;360:72-77.

23. Zis P, Martinez-Martin P, Sauerbier A, et al. Non-motor symptoms burden in treated and untreated early Parkinson's disease patients: argument for non-motor subtypes. Eur J Neurol. 2015;22(8):1145-1150.

24. Zis P, Rizos A, Martinez-Martin P, et al. Non-motor symptoms profile and burden in drug naive versus long-term Parkinson's disease patients. J Parkinson's Dis. 2014;4(3):541-547.

25. Chaudhuri KR, Odin P, Antonini A, Martinez-Martin P. Parkinson's disease: the non-motor issues. Parkinsonism Relat Disord. 2011;17(10):717-723.

26. Friedman JH, Chou KL. Sleep and fatigue in Parkinson's disease. Parkinsonism Relat Disord. 2004;10(Suppl 1):S27-S35.

27. Shulman LM, Taback RL, Bean J, Weiner WJ. Comorbidity of the nonmotor symptoms of Parkinson's disease. Mov Disord. 2001;16(3):507-510.

28. Friedman JH, Friedman H. Fatigue in Parkinson's disease: a nine-year follow-up. Mov Disord. 2001;16(6):1120-1122.

29. Saltiel PF, Silvershein DI. Major depressive disorder: mechanism-based prescribing for personalized medicine. Neuropsychiatr Dis Treat. 2015;11:875-888.

30. Prakash KM, Nadkarni NV, Lye WK, Yong MH, Chew LM, Tan EK. A longitudinal study of non-motor symptom burden in Parkinson's disease after a transition to expert care. Parkinsonism Relat Disord. 2015;21(8):843-847.

31. Valkovic P, Harsany J, Hanakova M, Martinkova J, Benetin J. Nonmotor symptoms in early- and advanced-stage Parkinson's disease patients on dopaminergic therapy: how do they correlate with quality of life? ISRN Neurol. 2014;2014:587302.

32. Rios Romenets S, Creti L, Fichten C, et al. Doxepin and cognitive behavioural therapy for insomnia in patients with Parkinson's disease - a randomized study. Parkinsonism Relat Disord. 2013;19(7):670-675.

33. Trotti LM, Bliwise DL. Treatment of the sleep disorders associated with Parkinson's disease. Neurotherapeutics. 2014;11(1):68-77.

34. Pal PK, Calne S, Samii A, Fleming JA. A review of normal sleep and its disturbances in Parkinson's disease. Parkinsonism Relat Disord. 1999;5(1-2):1-17.

35. Martinez-Ramirez D, De Jesus S, Walz R, et al. A polysomnographic study of Parkinson's disease sleep architecture. Parkinson's Dis. 2015;2015:570375.

36. Gaba DM, Howard SK. Patient safety: fatigue among clinicians and the safety of patients. $N$ Engl J Med. 2002;347(16):1249-1255.

37. Weinstein DF. Duty hours for resident physicians - tough choices for teaching hospitals. $N$ Engl J Med. 2002;347(16):1275-1278.
38. Steinbrook R. The debate over residents' work hours. $N$ Engl J Med. 2002;347(16):1296-1302.

39. Kluger BM, Herlofson K, Chou KL, et al. Parkinson's disease-related fatigue: a case definition and recommendations for clinical research. Mov Disord. 2016;31(5):625-631.

40. Barsevick AM, Irwin MR, Hinds P, et al. Recommendations for highpriority research on cancer-related fatigue in children and adults. $J$ Natl Cancer Inst. 2013;105(19):1432-1440.

41. Fukuda K, Straus SE, Hickie I, Sharpe MC, Dobbins JG, Komaroff A. The chronic fatigue syndrome: a comprehensive approach to its definition and study. International Chronic Fatigue Syndrome Study Group. Ann Int Med. 1994;121(12):953-959.

42. Friedman JH, Alves G, Hagell P, et al. Fatigue rating scales critique and recommendations by the Movement Disorders Society task force on rating scales for Parkinson's disease. Mov Disord. 2010;25(7):805-822.

43. Dittner AJ, Wessely SC, Brown RG. The assessment of fatigue: a practical guide for clinicians and researchers. J Psychosom Res. 2004; 56(2):157-170.

44. Cella D, Yount S, Sorensen M, Chartash E, Sengupta N, Grober J. Validation of the Functional Assessment of Chronic Illness Therapy Fatigue Scale relative to other instrumentation in patients with rheumatoid arthritis. J Rheumatol. 2005;32(5):811-819.

45. Smets EM, Garssen B, Bonke B, De Haes JC. The Multidimensional Fatigue Inventory (MFI) psychometric qualities of an instrument to assess fatigue. J Psychosom Res. 1995;39(3):315-325.

46. Lou JS, Kearns G, Oken B, Sexton G, Nutt J. Exacerbated physical fatigue and mental fatigue in Parkinson's disease. Mov Disord. 2001; 16(2):190-196.

47. Fisk JD, Doble SE. Construction and validation of a fatigue impact scale for daily administration (D-FIS). Qual Life Res. 2002;11(3): 263-272.

48. Guy W. Clinical global impression. ECDEU Assessment Manual for Psychopharmacology. Rockville, MD: National Institute of Mental Health; 1976.

49. Goetz CG, Tilley BC, Shaftman SR, et al. Movement Disorder Societysponsored revision of the Unified Parkinson's Disease Rating Scale (MDS-UPDRS): scale presentation and clinimetric testing results. Mov Disord. 2008;23(15):2129-2170.

50. Kluger BM, Brown RP, Aerts S, Schenkman M. Determinants of objectively measured physical functional performance in early to mid-stage Parkinson disease. PM R. 2014;6(11):992-998.

51. Lou JS, Kearns G, Benice T, Oken B, Sexton G, Nutt J. Levodopa improves physical fatigue in Parkinson's disease: a double-blind, placebo-controlled, crossover study. Mov Disord. 2003;18(10):1108-1114

52. Elbers RG, Verhoef J, van Wegen EE, Berendse HW, Kwakkel G. Interventions for fatigue in Parkinson's disease. Cochrane Database Syst Rev. 2015;10:CD010925.

53. Chou KL, Persad CC, Patil PG. Change in fatigue after bilateral subthalamic nucleus deep brain stimulation for Parkinson's disease. Parkinsonism Relat Disord. 2012;18(5):510-513.

54. Postuma RB, Lang AE, Munhoz RP, et al. Caffeine for treatment of Parkinson disease: a randomized controlled trial. Neurology. 2012;79(7):651-658.

55. Mendonca DA, Menezes K, Jog MS. Methylphenidate improves fatigue scores in Parkinson disease: a randomized controlled trial. Mov Disord. 2007;22(14):2070-2076.

56. Sheng P, Hou L, Wang X, et al. Efficacy of modafinil on fatigue and excessive daytime sleepiness associated with neurological disorders: a systematic review and meta-analysis. PLoS One. 2013;8(12):e81802.

57. Stocchi F, Fossati C, Torti M. Rasagiline for the treatment of Parkinson's disease: an update. Expert Opin Pharmacother. 2015;16(14):2231-2241.

58. Rascol O, Fitzer-Attas CJ, Hauser R, et al. A double-blind, delayedstart trial of rasagiline in Parkinson's disease (the ADAGIO study): prespecified and post-hoc analyses of the need for additional therapies, changes in UPDRS scores, and non-motor outcomes. Lancet Neurol. 2011;10(5):415-423. 
59. Schifitto G, Friedman JH, Oakes D, et al. Fatigue in levodopa-naive subjects with Parkinson disease. Neurology. 2008;71(7):481-485.

60. Ray Chaudhuri K, Martinez-Martin P, Antonini A, et al. Rotigotine and specific non-motor symptoms of Parkinson's disease: post hoc analysis of RECOVER. Parkinsonism Relat Disord. 2013;19(7): 660-665.

61. Zagmutt FJ, Tarrants ML. Indirect comparisons of adverse events and dropout rates in early Parkinson's disease trials of pramipexole, ropinirole, and rasagiline. Int J Neurosci. 2012;122(7):345-353.

62. Ondo WG, Shinawi L, Davidson A, Lai D. Memantine for non-motor features of Parkinson's disease: a double-blind placebo controlled exploratory pilot trial. Parkinsonism Relat Disord. 2011;17(3): $156-159$.

63. Russell IJ, Holman AJ, Swick TJ, et al. Sodium oxybate reduces pain, fatigue, and sleep disturbance and improves functionality in fibromyalgia: results from a 14-week, randomized, double-blind, placebocontrolled study. Pain. 2011;152(5):1007-1017.

64. Ondo WG, Perkins T, Swick T, et al. Sodium oxybate for excessive daytime sleepiness in Parkinson disease: an open-label polysomnographic study. Arch Neurol. 2008;65(10):1337-1340.

65. McNeely ME, Duncan RP, Earhart GM. Impacts of dance on non-motor symptoms, participation, and quality of life in Parkinson disease and healthy older adults. Maturitas. 2015;82(4):336-341.

66. Abrantes AM, Friedman JH, Brown RA, et al. Physical activity and neuropsychiatric symptoms of Parkinson disease. J Geriatr Psychiatry Neurol. 2012;25(3):138-145.

67. Cugusi L, Solla P, Zedda F, et al. Effects of an adapted physical activity program on motor and non-motor functions and quality of life in patients with Parkinson's disease. NeuroRehabilitation. 2014;35(4): 789-794.
68. Canning CG, Allen NE, Dean CM, Goh L, Fung VS. Home-based treadmill training for individuals with Parkinson's disease: a randomized controlled pilot trial. Clin Rehabil. 2012;26(9):817-826.

69. Winward C, Sackley C, Meek C, et al. Weekly exercise does not improve fatigue levels in Parkinson's disease. Mov Disord. 2012;27(1):143-146.

70. Cugusi L, Solla P, Serpe R, et al. Effects of a Nordic Walking program on motor and non-motor symptoms, functional performance and body composition in patients with Parkinson's disease. NeuroRehabilitation. 2015;37(2):245-254.

71. Kluger BM, Rakowski D, Christian M, et al. Randomized, controlled trial of acupuncture for fatigue in Parkinson's disease. Mov Disord. In press 2016.

72. Ghahari S, Leigh Packer T, Passmore AE. Effectiveness of an online fatigue self-management programme for people with chronic neurological conditions: a randomized controlled trial. Clin Rehabil. 2010;24(8):727-744.

73. Cochrane GD, Rizvi S, Abrantes AM, Crabtree B, Cahill J, Friedman JH. The association between fatigue and apathy in patients with either Parkinson's disease or multiple sclerosis. Parkinsonism Relat Disord. 2015;21(9):1093-1095.

74. Lou JS, Dimitrova DM, Park BS, et al. Using modafinil to treat fatigue in Parkinson disease: a double-blind, placebo-controlled pilot study. Clin Neuropharmacol. 2009;32(6):305-310.

75. Ondo WG, Fayle R, Atassi F, Jankovic J. Modafinil for daytime somnolence in Parkinson's disease: double blind, placebo controlled parallel trial. J Neurol Neurosurg Psychiatry. 2005;76(12):1636-1639.

76. Tyne HL, Taylor J, Baker GA, Steiger MJ. Modafinil for Parkinson's disease fatigue. J Neurol. 2010;257(3):452-456.

77. Olanow CW, Rascol O, Hauser R, et al. A double-blind, delayed-start trial of rasagiline in Parkinson's disease. NEngl JMed. 2009;361(13):1268-1278.
Journal of Parkinsonism and Restless Legs Syndrome

\section{Publish your work in this journal}

Journal of Parkinsonism and Restless Legs Syndrome is an online, open access, peer-reviewed journal. The journal publishes review articles, historical reviews, original research articles, case reports, letters to the editor, clinical teaching cases, neuroradiology highlights, neuropathology highlights, neuropsychiatry highlights, autobiographies, conference

\section{Dovepress}

proceedings, abstracts and book reviews. The manuscript management system is completely online and includes a very quick and fair peerreview system, which is all easy to use. Visit http://www.dovepress.com/ testimonials.php to read real quotes from published authors. 